\title{
Obtenção e caracterização de biodiesel e ecodieseis de girassol
}

\author{
Tamara Miranda de Moura* (Graduanda em Química na UERN); \\ Antônio Alex de Lima Silva ( Mestrando em Ciências Naturais do PPGCN na UERN); \\ Marilia Gabriela Araújo Pereira (Graduanda em Química na UERN); \\ Miguel Martins dos Santos Neto (Graduanda em Química na UERN); \\ Luiz Di Souza (Prof. Ad. do Dq e do PPGCN na UERN); \\ Anne Gabriella Dias Santos Caldeira (Profa . Ad. do Dq e do PPGCN NA UERN); \\ *thammyblz@gmail.com
}

\begin{abstract}
Resumo
O petróleo é um elemento que influência as relações contemporâneas do mundo, desde que se tornou a matriz energética básica da sociedade. Porém com a crise do petróleo e o surgimento de movimentos ambientalistas, vem-se procurando alternativas energéticas a fim de diminuir a dependência centrada nos combustíveis fósseis. Neste sentido o biodiesel se apresenta como uma alternativa viável, devido ao fato ser originado de biomassa renovável. No Brasil, é obrigado por lei que 7\% de biodiesel seja adicionado ao diesel, e a tendência é aumento dessa quantidade. Atrelado a isso surge à necessidade de matérias-primas alternativas como o girassol, começarem a ser utilizadas em maior escala para a síntese de biodiesel e produção de ecodiesel necessário ao atendimento da legislação. O girassol apresenta-se como opção viável no Nordeste, devido a sua adaptação às diversas condições dessa região com boa produtividade. Neste sentido aumenta-se a necessidade de melhorar os processos de síntese e de análise das propriedades físico-químicas e estruturais de seu biodiesel e dos ecodieseis produzidos com ele. Este trabalho analisou as propriedades físico-químicas e as características estruturais do biodiesel de girassol e de suas misturas (ecodiesel) com diesel de petróleo. $\mathrm{O}$ biodiesel foi sintetizado via transesterificação, utilizando a catálise homogênea básica e as misturas foram feitas nas concentrações de 2.5, 7.5, 10, 25, 50, 75 \% de biodiesel em diesel puro. Foram analisados os índices de iodo e peróxido, também realizados a caracterização por espectroscopia na região do infravermelho e análises térmicas. A Análise termogravimétrica mostrou uma conversão dos triglicerídeos em ésteres metílicos de $98,1 \%$, conversão acima do recomendado (96\%). As análises de índice de iodo e peróxido realizadas nas misturas mostraram que à medida que se aumenta a quantidade biodiesel nas misturas o material se torna mais susceptíveis a oxidação, isso ocorre devido a quantidade de ácidos graxos insaturados presente na matéria prima utilizada na produção do biodiesel. Pode se concluir que ocorreu a conversão de óleo em biodiesel, tanto por FT-IR que apresentou as absorções típicas dos ésteres em todas as misturas, quanto por TG que apresentou uma enorme diferença nos pontos de volatilização do óleo em comparação com o do éster. As análises de índice de iodo e peróxido mostram que medida que se aumenta a quantidade biodiesel nas misturas, o mesmo se tornam mais susceptíveis a oxidação.
\end{abstract}

\section{Palavras-chave:}

Girassol; Biodiesel; Ecodiesel

Espaço reservado para organização do congresso. 


\section{1- I NTRODUÇÃO}

O petróleo é um elemento de influência nas relações contemporâneas do mundo, desde quando se tornou a matriz energética básica da sociedade industrial e da economia moderna (BARROS, 2007; SUAREZ E MENEGHETTI, 2007; DABDOUB, BRONZEL E RAMPIN 2009). Porém com a crise do petróleo na década 70 e com o surgimento de movimentos ambientalistas vem-se procurando alternativas energéticas a fim de diminuir a dependência centrada nos combustíveis de origem fóssil.

Com esse objetivo no Brasil foi criado o Programa Nacional do Álcool (PROALCOOL), que teve como objetivo de incentivar a produção e o consumo de álcool como combustível (ANP, 2014). Porém o programa atende somente a demanda de carros de passeios, já que o álcool não é usado em caminhões e ônibus de grande porte.

Por meio da Medida Provisória $n^{\circ}$. 214/2004 (BRASIL, 2004), posteriormente convertida na Lei $\mathrm{n}^{\circ}$. 11.097/05(BRASIL, 2005), buscou-se estimular a produção e o consumo de biodiesel no Brasil para atender esta demanda de carros pesados movidos a diesel. Tal lei faz parte do Programa Nacional de Produção e Uso do Biodiesel (PNPB) (MATTEI, 2008). Como a maioria da produção brasileira é transportada por caminhões movidos a diesel, o biodiesel recebeu essa atenção devido a sua grande importância para o desenvolvimento econômico do Brasil (SILVA et al, 2015). A principal diretriz do programa é implantar gradativamente uma fonte de energia sustentável, a partir da produção e uso do biodiesel, promovendo a inclusão social, preços competitivos, produto de qualidade e com garantia de abastecimento ao longo dos anos (MATTEI, 2008).

A mistura de biodiesel ao diesel fóssil teve início compulsoriamente pela Lei $\mathrm{N}^{\circ} 11097$ de 13 de Janeiro de 2005 (BRASIL, 2005), onde biocombustíveis derivados de óleos e gorduras foram inseridos na matriz energética brasileira. Segundo essa lei estava previsto o uso opcional de B2 (2\% de biodiesel e 98\% de diesel de petróleo) até o início do ano de 2008, quando passou a ser obrigatório, de acordo com o PNPB. Com o perceptível amadurecimento do mercado brasileiro, esse percentual foi ampliado pelo Conselho Nacional de Política Energética (CNPE) sucessivamente até atingir 5\% (B5) (LOPES et al., 2008; BRASIL, 2009). Atualmente o percentual atual obrigatório de mistura de biodiesel ao óleo diesel é de 7\%. Essa decisão foi tomada pela Agência Nacional de Petróleo, Gás Natural e Biocombustíveis (ANP), regulamentada pela revisão da resolução ANP $n^{0}$ 14/2012, ocorrido em duas parcelas onde a partir de $1^{\circ}$ de julho de 2014 o teor aumentou para 6\% e dia $1^{\circ}$ de novembro de 2014 para $7 \%$. (BRASIL, 2014). A intenção do governo brasileiro é aumentar o teor de biodiesel na mistura ao longo dos anos, o que vai promover um aumento na demanda de matérias-primas para a produção de biodiesel. (BRASIL, 2008). Assim, se faz necessário estudar o comportamento dessas porcentagens e de outras maiores de biodiesel ao diesel, de forma a verificar se elas atendem a qualidade exigida e ou prever as consequências de tal aumento nesta qualidade.

Segundo a ANP no boletim de fevereiro de 2014 a maior parte do biodiesel produzido no Brasil é proveniente do óleo de soja. Neste contexto, com o possível aumento da produção brasileira de biodiesel, surge à necessidade do uso de matérias-primas alternativas em maior escala. O Brasil devido a sua grande área territorial cultivável apresenta vantagens para produção de oleaginosas promissoras para a produção de biocombustíveis, sendo essas produzidas em diferentes regiões a depender da forma de cultivo, clima, solo e zoneamento existente. (PINTO, 2014)

Neste sentido o girassol (helianthus annuus) se mostra promissor na produção de biodiesel, pois possui uma cultura de ampla capacidade de adaptação às diversas condições, possui baixa incidência de insetos e doenças, trás benefícios às culturas subsequentes e beneficia a agricultura familiar levando ao desenvolvimento regional por meio de geração de emprego e renda para os pequenos agricultores locais. (BELTRÃO; OLIVEIRA, 2007; BELTRÃO; OLIVEIRA, 2008; SANTOS, 2010).

Associado ao aumento na produção de biodiesel a partir do óleo de girassol existe a necessidade de melhorar os processos de síntese e análise das propriedades físico-químicas e estruturais do biodiesel e ecodiesel produzidos com ele. 
Neste contexto a espectroscopia de infravermelho é uma técnica analítica não-destrutiva que permite a determinação rápida, direta e segura de diversas propriedades, sem pré-tratamento da amostra. Características que fazem uso dessa técnica útil na indústria do petróleo para determinação de propriedades físicas e químicas de combustíveis e seus derivados, bem como para controlar a qualidade do biodiesel e de suas misturas com ecodiesel (ALISKE, 2010). O que proporciona análise de componentes principais em regiões do infravermelho médio é viável para identificar contaminação com óleo vegetal no processo de produção e para revelar misturas ilegais de petrodiesel com óleo vegetal (GALVÃO, 2007; GONDIM, 2009).

A análise térmica consiste em um grupo de técnicas nas quais as propriedades física e/ou químicas de uma substância são medidas em função da temperatura, enquanto a substância é submetida a uma temperatura constante ou a um programa de aumento controlado de temperatura, numa atmosfera especifica (MOURA, 2008; GONDIM, 2009; SANTOS, 2010). Neste sentido a termogravimetria (TG) é usada para avaliar a mudança na massa de um dado material, sob aquecimento ou resfriamento a uma velocidade controlada, com variáveis de tempo e/ou temperatura também controladas (SOUZA, 2005). Os métodos térmicos permitem efetuar a determinação de várias propriedades dos materiais, tais como: estabilidade térmica, porcentagem de água fisissorvida/químissorvida, caracterização do catalisador, cristalização, etc. (HARRIS, et al, 2005).

Tendo em vista isso, este trabalho teve como objetivo analisar as propriedades físicoquímicas e térmicas e as características estruturais do biodiesel de girassol e de suas misturas com diesel de petróleo, verificando como os parâmetros se modificam à medida que aumenta a $\%$ de biodiesel.

\section{2- MATERI AIS E METODOS}

\subsection{Preparação do biodiesel}

A síntese do biodiesel foi realizada com óleo de girassol comercial. A reação de transesterificação ocorreu pela rota metílica utilizando-se a catálise homogênea básica e razão molar 1:6 de óleo/álcool metílico. Foi acrescentado excesso de álcool para favorecer a reação, sendo um dos fatores relevantes para se obter um bom rendimento na reação. $\mathrm{O}$ catalisador utilizado na reação foi o hidróxido de potássio $(\mathrm{KOH})$, na concentração de $1 \%$ com base na massa de óleo. Vale salientar que antes das reações, o óleo passou por um pré-tratamento, onde foi seco em estufa na temperatura de $100{ }^{\circ} \mathrm{C}$, por três horas, com a finalidade de retirar a umidade. O biodiesel obtido foi denominado de BP (biodiesel puro).

Para a síntese inicialmente colocou-se o óleo em um béquer, mantendo-o em constante agitação com o auxilio de um agitador mecânico. A parte realizou-se a preparação do metóxido de potássio, misturando-se o metanol ao hidróxido de potássio e agitando-o constantemente até total dissolução. Posteriormente essa solução foi acrescentada ao béquer, permanecendo em agitação por 2 horas a temperatura ambiente. Ao término da reação, a mistura foi transferida para um funil de decantação, para separação das duas fases. Após uma hora, percebeu-se nitidamente a separação de duas fases, uma mais clara e menos densa na parte superior (ésteres metílicos), e outra mais escura e densa na parte inferior (glicerina), como se pode visualizar claramente na Figura 1.

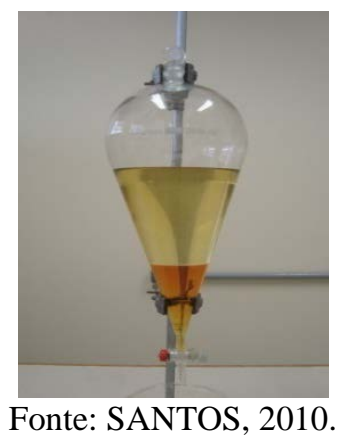

Figura 1- Fotografia mostrando a separação do biodiesel após a reação de transesterificação. 
Após, 24 horas decantando a glicerina foi removida, restando apenas os ésteres metílicos que passaram por um processo de lavagem com água morna, sendo esta feita abundantemente. $\mathrm{O}$ controle deste processo foi realizado pela medida do $\mathrm{pH}$ da água residual, sendo que ao ocorrer a viragem da cor (passagem da cor rosa para incolor da fenolftaleína), o procedimento foi finalizado. Em seguida, o biodiesel foi seco numa estufa a $100^{\circ} \mathrm{C}$ para eliminação de umidade e metanol residual. (SANTOS, 2010, OLIVEIRA, et al, 2012a; OLIVEIRA, et al, 2012 b)

\subsection{Mistura do biodiesel no diesel}

As preparações dos ecodieseis foram feitas a partir da adição de biodiesel de girassol ao diesel mineral proporção de B2.5, B7.5, B10, B25, B50 e B75. O óleo diesel puro para as misturas foi gentilmente cedido pela Petrobrás, devido ao fato do comercial já conter o biodiesel adicionado. As misturas foram realizadas nas proporções massa de biodiesel/massa de diesel, utilizando-se uma balança analítica para o processo. Nas misturas foram realizadas as análises de índice de iodo e peróxido para avaliar sua estabilidade, além da análise de infravermelho e análise termogravimétrica para verificar a formação do biodiesel. As metodologias realizadas para estas propriedades foram baseadas nos trabalhos de SANTOS (2010); PINTO (2014); SILVA, et al (2015) que são descritas resumidamente a seguir.

\section{3 Índice de iodo}

Neste parâmetro pesou-se cerca de $1 \mathrm{~g}$ das amostras em um Erlenmeyer de $500 \mathrm{~mL}$ seguido da adição de $10 \mathrm{ml}$ de tetracloreto de carbono, em seguida foi adicionado $25 \mathrm{~mL}$ da solução Wijs e agitou-se cuidadosamente. Deixou-se a mistura em repouso por 30 minutos ao abrigo da luz na temperatura ambiente, após esse tempo adicionou-se $10 \mathrm{~mL}$ de uma solução de iodeto de potássio a $15 \%$ e $100 \mathrm{~mL}$ de água recentemente fervida e resfriada e titulou-se com Tiossulfato de sódio 0,1N, adicionando-o lentamente sobre agitação constante até uma fraca coloração amarela, ao atingir a coloração, foi adicionado $2 \mathrm{~mL}$ da solução de amido e continuou-se a titulação até desaparecimento da coloração cor azul. O índice foi calculado pela equação 1e o branco foi uma solução com todos os reagentes, exceto a amostra:

$$
\mathrm{II}=\frac{\mathrm{V} \times \mathrm{FC} \times 1,27}{\mathrm{P}}
$$

Equação 1

Onde:

$\mathrm{V}=$ diferença (em $\mathrm{mL}$ ) de tiossulfato de sódio 0,1N gastos nas duas titulações (branco e amostra). $\mathrm{FC}=$ fator de correção da solução de tiossulfato de sódio $0,1 \mathrm{~N}$.

$\mathrm{P}=$ massa em gramas da amostra.

\section{4 Í ndice de peróxido}

Para essa análise pesou-se cerca de $5 \mathrm{~g}$ de amostra em um Erlenmeyer de $250 \mathrm{~mL}$, Adicionou-se $30 \mathrm{~mL}$ de uma mistura de ácido acético e clorofórmio (3:2) e Agitou-se até dissolução da amostra, em seguida foi adicionado $0,5 \mathrm{~mL}$ de solução saturada de iodeto de potássio e agitouse durante um minuto, logo após acrescentou-se $30 \mathrm{~mL}$ de água destilada e titulou-se com uma solução de tiossulfato de sódio $0,1 \mathrm{~N}$, até o ponto levemente alaranjado, após atingir a coloração adicionou-se $5 \mathrm{~mL}$ de uma solução de amido a 1\% e continuou a titulação até o desaparecimento da cor azul. O índice foi calculado pela equação 2 e o branco foi uma solução com todos os reagentes, exceto a amostra:

Onde:

$$
I P=\frac{V \times N \times 1000 \times F C}{P} \quad \text { Equação } 2
$$

$\mathrm{V}=$ diferença $(\mathrm{em} \mathrm{mL}$ ) de tiossulfato de sódio de sódio $0,1 \mathrm{~N}$ gastos nas duas titulações (amostra e branco).

$\mathrm{FC}=$ fator de correção do tiossulfato de sódio de sódio $0,1 \mathrm{~N}$.

$\mathrm{P}=$ massa em gramas da amostra. 
N= Normalidade da solução de Tiossulfato de sódio.

\subsection{Termogravimetria (TG/ DTG)}

A análise termogravimétrica (TG/DTG) foi realizada com intuito de estudar a estabilidade térmica e o processo de vaporização e decomposição do óleo e biodiesel, bem como analisar a conversão em ésteres metílicos. Na obtenção dos resultados utilizou-se uma termobalança, marca Mettler Toledo, modelo TGA/SDTA-851, com uma faixa de temperatura de 30 a $600^{\circ} \mathrm{C}$, com de razão de aquecimento $10^{\circ} \mathrm{C} / \mathrm{min}$, sob atmosfera inerte de Hélio, com vazão de 25 $\mathrm{mL} / \mathrm{min}$. Para realização da análise foi utilizado cadinho de alumina de $900 \mu \mathrm{L}$ e massa da amostra de aproximadamente $75 \mathrm{mg}$. (SANTOS, 2010)

\subsection{Espectroscopia de absorção na região do infravermelho}

De modo a caracterizar estruturalmente o biodiesel e suas misturas, foi realizada a análise de espectroscopia na região do infravermelho. Em resumo a técnica mede a transição do estado vibracional que ocorre quando uma molécula absorve energia na região do infravermelho do espectro eletromagnético. A caracterização estrutural do biodiesel de girassol e das respectivas misturas foram realizadas no UIV-vis foi realizada usando janela de $\mathrm{KBr}$ (apropriadas para amostras líquidas) e um Espectrômetro de Infravermelho Médio por Transformação de Fourrier (FT-IR) da BOMEN, modelo ABB, série MB 104, na faixa de 4000-400 $\mathrm{cm}^{-1}$ com resolução de $4 \mathrm{~cm}^{-1}$ (GONDIM, 2009, ALISKE, 2010).

\section{3- RESULTADOS E DI SCUSSÃO}

Com base nos resultados da análise termogravimétrica apresentada no gráfico 1 (em preto) pode-se observar que a curva referente ao óleo de girassol, apresenta uma única perda de massa. Essa etapa é atribuída à volatilização e/ou decomposição dos triglicerídeos, presentes no óleo de girassol que tem como ácido graxo majoritário o linoleico. Quando observado a curva do biodiesel o comportamento é semelhante, pois apresenta uma única perda de massa, a qual é referente à volatilização, dos ésteres metílicos formados na reação de transesterificação. No gráfico 1, nota-se que a volatilização do biodiesel de girassol ocorre em temperaturas menores em relação ao óleo de girassol, o que indica a formação de biodiesel já que a transesterificação elimina ou diminui a possibilidade de formação de ligações de hidrogênio e assim causa um abaixamento nas temperaturas de volatilização dos ésteres (OLIVEIRA, et al, 2012 b). Como mostra a tabela1, a perda de massa da amostra de biodiesel, foi de 98,1\%, essa porcentagem, mostra que a conversão dos triglicerídeos em ésteres metílicos foi muito boa e que a conversão está dentro dos padrões exigidos na legislação (maior que 96 \%) (BRASIL, 2012). Os resultados indicam ainda que as amostras são de alta pureza e que o óleo de girassol tem excelente estabilidade térmica na temperatura de síntese usada.

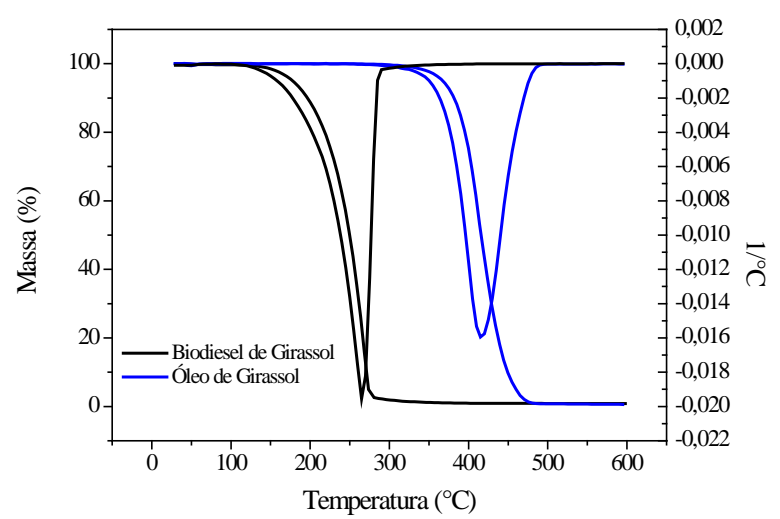

Gráfico 1- TG/DTG para do óleo de girassol e seu respectivo biodiesel. 
Tabela 1- Perdas de massa, faixa onde ocorre a perda, temperatura de perda máxima e de resíduos do óleo de girassol e seu biodiesel.

\begin{tabular}{|c|c|c|c|c|c|}
\hline Amostras & & $\mathbf{T}\left({ }^{\circ} \mathrm{C}\right)$ & $\begin{array}{l}\mathbf{T}_{\text {máx }} \\
\left({ }^{\circ} \mathrm{C}\right)\end{array}$ & $\begin{array}{l}\text { Perda de } \\
\text { Massa (\%) }\end{array}$ & $\begin{array}{l}\text { Massa } \\
\text { Residual }\end{array}$ \\
\hline Óleo de Girassol & & $300-495$ & 415 & 98.7 & 1.3 \\
\hline Biodiesel & de & $115-315$ & 265 & 98.1 & 1.9 \\
\hline
\end{tabular}

Nas misturas e no biodiesel puro foram realizadas as análises de índice de iodo e peróxido em função do \% de biodiesel, onde o comportamento destes parâmetros podem ser visualizados nos gráficos 2 e 3 .

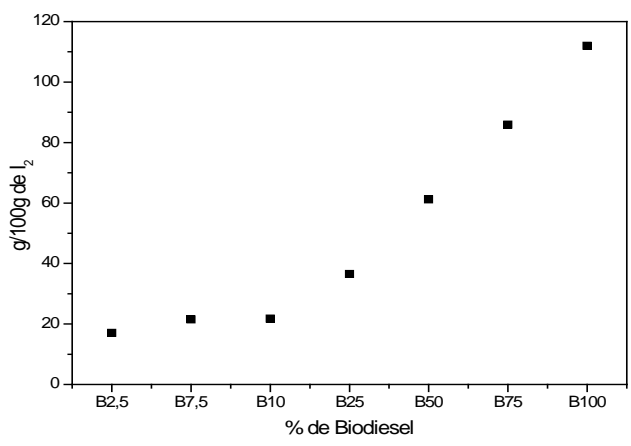

Gráfico 2- Índice de iodo em função da \% de Biodiesel no ecodiesel.

O índice de iodo está diretamente relacionado com o total de insaturações de um material lipídico, ou seja, o índice de iodo aumenta com o aumento na proporção de insaturações (BOUAID et al., 2007). Conforme mostrado no gráfico 2, a medida que se aumenta o teor de biodiesel na mistura, o índice aumenta, e atinge um máximo no B100 (biodiesel puro). Esse comportamento pode ser explicado com base nos ácidos graxos presente no óleo de girassol que em sua maioria possuem no mínimo uma instauração em suas cadeias carbônicas, o que contribui, consideravelmente, para o aumento deste parâmetro, visto que quase $80 \%$ do óleo é formado por compostos insaturados, como pode ser visualizado na tabela 2.

Tabela 2- Principais ácidos graxos presente do óleo de girassol

\begin{tabular}{cc}
\hline $\begin{array}{c}\text { Ácidos Graxos presentes do } \\
\text { óleo de girassol }\end{array}$ & \% \\
\hline Mirístico (C14: 0) & 0,8 \\
Palmítico (C16: 0) & 8,4 \\
Palmitoléico (C16: 1) & 0,064 \\
Esteárico (C18: 0) & 0.02 \\
Óleico (C18: 1) & 26,96 \\
Linoléico (C18: 2) & 49,47 \\
Linolênico (C18: 3) & 2,64 \\
Eicosanôico (C20: 0) & 0,63 \\
Docosanôico (C22: 0) & 1,75 \\
Erucate (C22: 1) & 0,65 \\
Tretracosanôico (C24: 0) & 0,23 \\
Outros & 5.736 \\
Total de Insaturados & 79,78 \\
Total de Saturados & 11,83 \\
\hline
\end{tabular}

Fonte: Santos, 2010 


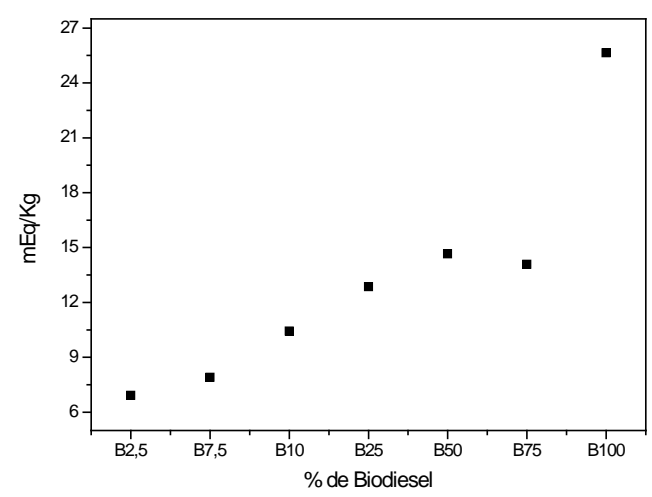

Gráfico 3- Índice de peróxido em função da \% de Biodiesel no ecodiesel

A oxidação é proveniente de sucessivas reações que ocorrem nas insaturações dos ésteres das cadeias graxas, proveniente da matéria prima utilizada, que em contato com oxigênio atmosférico, luz, temperatura, radiação ionizante e outros agentes oxidantes, podem acelerar o processo de formação de peróxidos e, consequentemente, outros produtos oxidativos (SANTOS 2010; PINTO, 2014).

Esse comportamento é observado para amostras sintetizadas neste trabalho, pois à medida que se aumenta o percentual de biodiesel nas misturas ocorre um aumento considerável do índice de peróxido, deixando claro que seu aumento leva o ecodiesel a ser mais facilmente oxidado. Esse resultado corrobora com os dados de índice de iodo visto que os únicos pontos que propiciam facilmente a oxidação é a instauração presente no biodiesel. Essas insaturações são provenientes dos ácidos graxos insaturados citados anteriormente na análise de índice de Iodo. Em resumo, para os dois parâmetros analisados, à medida que aumenta a quantidade de biodiesel, a mistura se torna menos estável e consequentemente mais susceptível a oxidação o que não é de interesse da indústria. Para a confirmação destes resultados se faz necessário à realização de análises da estabilidade oxidativa (OS) de modo há estimar o tempo que cada amostra leva para ser oxidada.

O gráfico 4 mostra os espectros de FT-IR da biodiesel e do diesel usados. Devido ao fato dos compostos possuírem diferentes tipos de ligações e grupos funcionais diferentes e algumas frequências e intensidades de absorções distintas pode-se com essa técnica verificar as diferentes frequências das amostras e usar a que se mostrar eficiente para controlar a \% de biodiesel no ecodiesel.

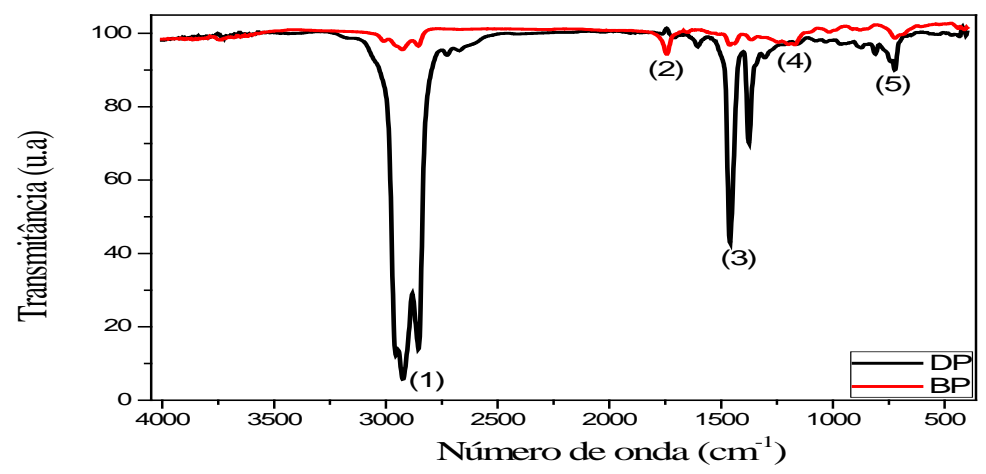

Gráfico 4- Espectros de FT-IR das amostras de óleo diesel e biodiesel de girassol 


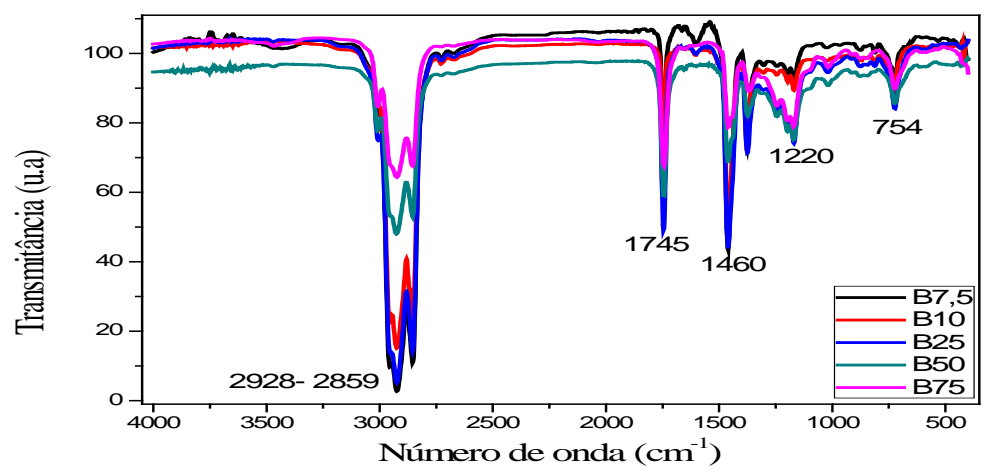

Gráfico 5- Espectros no infravermelho em função da \% de biodiesel no ecodiesel.

$\mathrm{Na}$ análise de infravermelho foram identificados as principais bandas referente às amostras analisadas:

$>$ (1) Entre 2928 - 2859 cm$^{-1}$ - Deformação axial da ligação H-C (saturado);

(2) $1745 \mathrm{~cm}^{-1}$ - Deformação axial da ligação dupla $\mathrm{C}=\mathrm{O}$;

(3) $1460 \mathrm{~cm}^{-1}$ - Deformação angular do grupo $\mathrm{CH}_{2}$;

(4) $1220 \mathrm{~cm}_{-}{ }^{1}$ - Deformação angular de C-C (=O)-O;

(5) $754 \mathrm{~cm}^{-1}$ - Deformação fora do plano do $\mathrm{CH}_{2}$.

No gráfico 4, está representado os espectros para o diesel e o biodiesel e pode-se se constatar que no diesel não aparece as principais absorções características do éster, na faixa de absorbância de $1745 \mathrm{~cm}^{-1}$ e $1220 \mathrm{~cm}_{-}{ }^{1}$ que é referente a deformação axial da ligação dupla $\mathrm{C}=\mathrm{O}$ e a deformação angular de C-C (=O)-O respectivamente. No entanto, em todas as misturas apresentadas no gráfico 5, estas bandas são observada. As intensidades das bandas não são proporcionais às concentrações de biodiesel, esse fato pode ser atribuído ao método empregado na preparação das amostras que mistura uma quantidade de amostra (1\% em $\mathrm{KBr}$ ) e depois se prepara pastilhas de $\mathrm{KBr}$ com essas misturas o que faz que as amostras preparadas sejam homogêneas quantitativamente. Assim a análise não pode ser feita de forma quantitativa, devido a quantidade de biodiesel não ser, necessariamente, proporcional à sua quantidade na amostra preparada para análise de FT-IR.

\section{4- CONCLUSÕES}

Com Base nos resultados, pode se concluir que ocorreu a conversão de óleo em biodiesel, tanto por FT-IR que apresentou as absorções típicas dos ésteres em todas as misturas, quanto por TG que apresentou uma enorme diferença nos pontos de volatilização do óleo em comparação com o do éster. Os resultados de TG também mostraram que a conversão foi muito alta, $(98,1 \%)$. As análises de índice de iodo e peróxido mostram que medida que se aumenta a quantidade biodiesel nas misturas, aumenta-se os valores desses parâmetros nos materiais, indicando que os mesmos se tornam mais susceptíveis a oxidação devido ao aumento das duplas ligações nos ecodieseis.

\section{Obtaining and characterization of biodiesel and sunflower biodiesel}

\section{Abstract}

Oil is an element that influence the contemporary relations in the world, since it is the basic energy matrix of society. But with the oil crisis and the emergence of environmental movements, comes to looking for alternative energy sources to reduce dependence on fossil fuels centered. In this sense the biodiesel itself as a viable alternative due to the fact originate from renewable biomass. In Brazil, it is bound by law to 7\% biodiesel is added to diesel, and the trend is increasing that amount. Coupled to this comes the need for alternative raw materials 
such as sunflower, began to be used on a larger scale for biodiesel synthesis and production ecodiesel necessary care legislation. Sunflower presents itself as a viable option in the Northeast, due to its adaptation to different conditions of this region with good productivity. In this sense increases the need to improve the processes of synthesis and analysis of physicochemical and structural properties of its biodiesel and ecodieseis produced with it. This study analyzed the physical and chemical properties and structural characteristics of sunflower biodiesel and mixtures (ecodiesel) with petroleum diesel. The biodiesel was synthesized via transesterification, using basic catalysis homogeneous and the mixtures were made at concentrations of $2.5,7.5,10,25,50,75 \%$ of biodiesel in diesel pure. The contents of iodine and peroxide also made to characterize by the infrared spectroscopy and thermal analysis were analyzed. Thermogravimetric analysis showed a conversion of triglyceride to methyl esters in 98.1\% conversion above the recommended (96\%). The iodine value analysis and peroxide carried in the mixtures show that as increasing the biodiesel amount in the mixture material becomes more susceptible to oxidation, this occurs because the amount of unsaturated fatty acids present in the raw materials used in production of biodiesel . It can be concluded that occurred biodiesel oil conversion, both by FT-IR which showed typical absorptions of esters in all mixtures, as TG which showed a large difference in oil volatilization points compared with the ester. The peroxide value and iodine analysis shows that as one increases the amount biodiesel blends, it becomes more susceptible to oxidation.

\section{Keywords}

sunflower; biodiesel; Ecodiesel.

\section{REFERENCI AS BI BLIOGRÁFI CAS}

AGÊNCIA NACIONAL DE PETRÓLEO, GÁS NATURAL E BIOCOMBUSTÍVEIS. Disponível em:< www.anp.gov.br>. Acesso em: 25 Janeiro de 2014 .

AGÊNCIA NACIONAL DE PETRÓLEO, GÁS NATURAL E BIOCOMBUSTÍVEIS. RESOLUÇÂO $\mathrm{n}^{0} \quad 7$, de 19/03/2008-DOU-20/03/2008. Disponível em: < http://www.anp.gov.br/biocombustiveis/biodiesel.asp>. Acesso em: 25 de Janeiro. 2014.

ALISKE, Marcelo Adriano. Medidas de Espectroscopia no Infravermelho Médio para a Determinação do Teor de Biodiesel em Óleo Diesel. Mestrado em Engenharia e Ciência dos Materiais, Universidade Federal do Paraná, 100p. 2010.

BARROS, Evandro Vieira de. Matriz Energética Mundial e a Competitividade das Nações: Bases de uma Nova Geopolítica. ENGEVISTA, V.9, №.1, 2007.

BELTRÃO, Napoleão Esberard de Macêdo; OLIVEIRA, Maria Isaura Pereira de. EMBRAPA ALGODÃO. Oleaginosas e seus óleos: Vantagens e Desvantagens para Produção de Biodiesel. Campina Grande, 2008.

BELTRÃO; Napoleão Esberard de Macêdo; OLIVEIRA; Maria Isaura Pereira de. Oleaginosas potencias do nordeste para produção de biodiesel, Documentos MAPA, N.177, Campina Grande - PB, 2007.

BOUAID, Abderrahim; MARTINEZ, Mercedes; ARACIL, José. Long storage stability of biodiesel from vegetable and used frying oils, Fuel, V.86, 2007.

BRASIL, Agência Nacional do Petróleo, Gás Natural e Biocombustíveis Revisão da Resolução ANP n ${ }^{\circ} 14 / 2012$ que trata da Especificação do biodiesel (B100) produzido e comercializado no território nacional, Rio de Janeiro, 07 de maio de 2014.

BRASIL, Conselho Nacional de Política Energética - CNPE, Resolução No 6, de 16 de setembro de 2009.

BRASIL. Lei $\mathrm{n}^{\circ}$. 11.097/05 13 de janeiro de 2005 Publicada no Diário Oficial da União em 13 de janeiro de 2005.

BRASIL, Agência Nacional de Petróleo, Gás Natural e Biocombustíveis, Resolução No 14 de 11 de Maio de 2012. Disponível em: www.anp.gov.br , acessado em 25 de Setembro de 2015.

DABDOUB, Miguel Joaquim; BRONZEL, João Luiz, e RAMPIN, Marcia Alexandra. Biodiesel: visão crítica do status atual e perspectivas na academia e na indústria. Química Nova, Vol. 32, No. 3, 776-792, São Paulo, 2009. 
GALVÃO, Luzia Patrícia Fernandes de Carvalho. Avaliação termoanalítica da eficiência de antioxidantes na estabilidade oxidativa do biodiesel de mamona, Mestrado em Química, UFRN, 159p., 2007.

GONDIM, Amanda Duarte. Avaliação da Estabilidade Térmica e Oxidativa do Biodiesel de Algodão. Doutorado em Química, UFRN, 249p., 2009.

MATTEI Lauro Francisco. Programa nacional para produção e uso do biodiesel no brasil (PNPB): trajetória, situação atual e desafios, anais de evento, $46^{\circ}$ congresso Sociedade Brasileira de Economia, Administração e Sociologia Rural, Rio branco, 2008.

OLIVEIRA, Daniela da Silva; et al, Obtenção do biodiesel através da transesterificação do óleo de moringa oleífera lam, HOLOS, V. 1, No 28, 2012(b)

OLIVEIRA, Francisco Adriano Góis. et al. Síntese, caracterização e avaliação de biodiesel de óleo de oiticica (Licania rigida benth) e isolalamento do éster metílico do ácido licânico, Química: ciência, tecnologia e sociedade, V.1, No 12012 (a).

PINTO, Vasco de Lima. Efeitos do envelhecimento na degradação termoxidativa do sebo bovino e seus biocombustiveis via analise de UV - VIS, Mestrado em Ciências Naturais, UERN, 151p., 2014

SANTOS, Anne Gabriella Dias. Avaliação da estabilidade térmica do biodiesel de algodão, girassol, dendê e sebo bovino, Mestrado em Química, UFRN, Natal, RN 2010.

SILVA, Antônio Alex de Lima, et al., Síntese e Caracterização de Biodiesel de Sebo Bovino e de sua Mistura B10, Orbital: Electron. J. Chem. V.7 No.12015.

LOPES, Afonso. et al. Biodiesel no brasil: aspectos gerais e síntese da legislação, Atualidades jurídicas, V.4, Nº.4, dez, 2008

SUAREZ, Paulo Anselmo Ziani; MENEGHETTI, Simoni Margareti Plentz. $70^{\circ}$ aniversário do biodiesel em 2007: evolução histórica e situação atual no Brasil. Química Nova, V.30, Nº.8, 2007.

SOUZA, Marcelo José Barros de. Desenvolvimento de catalisadores de cobalto e molibdênio suportados em materiais tipo MCM-41 para a hidrodessulfurização de frações de petróleo, Doutorado em Química, UFRN. 224 f., 2005.

HARRIS, Daniel C; Análise Química Quantitativa. 5. ed. Rio de Janeiro: LTC, 2005.

MOURA, Kátia. Regina Marques. Otimização do processo de produção de biodiesel metílico do Sebo bovino aplicando um delineamento composto central Rotacional (dccr) e a avaliação da estabilidade térmica, Doutorado em Química, UFPB. 2008. 